\title{
Epidermal Growth Factor and Fibroblast Growth Factor-2 Have Different Effects on Neural Progenitors in the Adult Rat Brain
}

\author{
H. Georg Kuhn, ${ }^{1}$ Jürgen Winkler, ${ }^{2,3}$ Gerd Kempermann, ${ }^{1}$ Leon J. Thal,, ${ }^{2,3}$ and Fred H. Gage ${ }^{1}$ \\ ${ }^{1}$ Laboratory of Genetics, The Salk Institute, La Jolla, California 92186, 2 Department of Neurosciences, University of \\ California San Diego, La Jolla, California 92093, and ${ }^{3}$ Neurology Service (127), Veterans Affairs Medical Center, La Jolla, \\ California 92161
}

\begin{abstract}
Neurons and glia are generated throughout adulthood from proliferating cells in two regions of the rat brain, the subventricular zone (SVZ) and the hippocampus. This study shows that exogenous basic fibroblast growth factor (FGF-2) and epidermal growth factor (EGF) have differential and site-specific effects on progenitor cells in vivo. Both growth factors expanded the SVZ progenitor population after 2 weeks of intracerebroventricular administration, but only FGF-2 induced an increase in the number of newborn cells, most prominently neurons, in the olfactory bulb, the normal destination for neuronal progenitors migrating from the SVZ. EGF, on the other hand, reduced the total number of newborn neurons reaching the olfactory bulb and substantially enhanced the generation of astrocytes in the olfactory bulb. Moreover, EGF increased the number of newborn cells in the striatum either by migration of SVZ cells or
\end{abstract}

by stimulation of local progenitor cells. No evidence of neuronal differentiation of newborn striatal cells was found by threedimensional confocal analysis, although many of these newborn cells were associated closely with striatal neurons. The proliferation of hippocampal progenitors was not affected by either growth factor. However, EGF increased the number of newborn glia and reduced the number of newborn neurons, similar to the effects seen in the olfactory bulb. These findings may be useful for elucidating the in vivo role of growth factors in neurogenesis in the adult CNS and may aid development of neuronal replacement strategies after brain damage.

Key words: subventricular zone; hippocampus; epidermal growth factor; basic fibroblast growth factor; intracerebroventricular administration; progenitor cells; stem cells; proliferation; neurogenesis; gliogenesis
The adult CNS appears to have only limited potential to generate new neurons, making it vulnerable to injury and disease. However, certain areas of the brain retain the capacity for neurogenesis well into adulthood (Altman and Das, 1965; Kuhn et al., 1996). In the adult rodent a rapidly dividing population of stem cells in the subventricular zone (SVZ) of the lateral ventricle generates all neural cell types: neurons, astrocytes, and oligodendrocytes (Lewis, 1968; Privat and Leblond, 1972; Corotto et al., 1993; Lois and Alvarez-Buylla, 1993; Morshead et al., 1994; Goldman, 1995; Hauke et al., 1995). From the SVZ neuronal progenitors migrate tangentially (sagittally) along the rostral migratory stream (RMS) into the olfactory bulb (OB), where they differentiate into granule and periglomerular neurons (Corotto et al., 1993; Lois and Alvarez-Buylla, 1993, 1994; Luskin, 1993; Goldman, 1995; Lois et al., 1996). In contrast, glial progenitor cells migrate radially into neighboring brain structures such as striatum, corpus callosum, and neocortex (Levison and Goldman, 1993; Levison et al., 1993; Luskin and McDermott, 1994). In the hippocampal dentate gyrus of adult rats, neural precursor cells continue to proliferate and differentiate into granule cells

Received Dec. 11, 1996; revised March 27, 1997; accepted May 9, 1997.

This work was supported by the National Institute on Aging, National Institutes of Health, Veterans Affairs Research Service, and Sam and Rose Stein Institute for Research on Aging. H.G.K. is a fellow of the Hereditary Disease Foundation. J.W. is a fellow of the National Brookdale Foundation. G.K. is a fellow of the Deutsche Forschungsgemeinschaft. We thank Gilbert Ramirez for his excellent technical assistance and Theo D. Palmer, Lisa J. Fisher, Mireya Nadal-Vicens, and Mary Lynn Gage for their critical review of this manuscript.

H.G.K. and J.W. have contributed equally to this manuscript.

Correspondence should be addressed to Dr. Fred H. Gage, The Salk Institute, Laboratory of Genetics, P.O. Box 85800, San Diego, CA 92186-5800.

Copyright (C) 1997 Society for Neuroscience $0270-6474 / 97 / 175820-10 \$ 05.00 / 0$
(Kaplan and Hinds, 1977; Kaplan and Bell, 1983; Cameron et al., 1993; Kuhn et al., 1996).

To be able to manipulate the endogenous adult progenitors, we believe it is crucial to determine the extracellular signals that can stimulate cell division and regulate the fate of these neural stem and progenitor cells (Cattaneo and McKay, 1991; Gage, 1994). Recently, several groups successfully have isolated and propagated adult neural progenitor cells in vitro (Reynolds and Weiss, 1992; Richards et al., 1992; Lois and Alvarez-Buylla, 1993; Vescovi et al., 1993; Morshead et al., 1994; Gage et al., 1995a; Palmer et al., 1995; Gritti et al., 1996). Dissociated cells from the SVZ and the hippocampus required basic fibroblast growth factor (FGF-2) or epidermal growth factor (EGF) for proliferation and long-term survival in vitro. Some of these cells retain the ability to generate both neurons and glia, suggesting that newborn cells of the adult brain may originate from stem cell-like progenitors (Morshead et al., 1994; Gage et al., 1995a; Palmer et al., 1995; Gritti et al., 1996; Suhonen et al., 1996).

The possibility that growth factors also may influence neural progenitors in vivo has been supported by findings that intracerebroventricular administration of EGF expanded proliferative progenitors in the SVZ of adult mice (Craig et al., 1996). Numerous newborn cells were found in the adjacent striatum, septum, and cortex, and a small portion of these cells expressed neuronal antigens.

The goal of the present study was to explore systematically the effects of FGF-2 or EGF on the proliferation and differentiation of neural progenitor cells in the SVZ/OB system and the dentate gyrus of adult rats. FGF-2, EGF, or artificial CSF (aCSF) were chronically infused into the lateral ventricle. The proliferative 
zones, migratory paths, and areas of neuronal differentiation were analyzed quantitatively for the number and phenotype of newborn cells.

\section{MATERIALS AND METHODS}

\section{Animals and surgery}

Male Fischer-344 albino rats $(n=30$; Harlan Sprague Dawley, Indianapolis, IN) were used in this experiment. The animals were 13-14 weeks old and weighed between 260 and $300 \mathrm{gm}$ at the start of the experiment. Anesthesia was induced by an intramuscular injection consisting of $62.5 \mathrm{mg} / \mathrm{kg}$ ketamine (Ketaset, $100 \mathrm{mg} / \mathrm{ml}$, Bristol Laboratories, Syracuse, NY), $3.175 \mathrm{mg} / \mathrm{kg}$ xylazine (Rompun, $20 \mathrm{mg} / \mathrm{ml}$, Miles Laboratories, Shawnee, KS), and $0.625 \mathrm{mg} / \mathrm{kg}$ acepromazine maleate $(10 \mathrm{mg} / \mathrm{ml}$, TechAmerica Group, Elwood, KS) dissolved in $0.9 \%$ sterile saline. Rats were mounted in a small animal stereotaxic apparatus (David Kopf, Tujunga, CA) with bregma and lambda in the same horizontal plane. A stainless steel cannula (28 gauge, Plastic Products, Roanoke, VA) was implanted in the lateral ventricle [anteroposterior (AP) $+8.5 \mathrm{~mm}$, lateral $+1.5 \mathrm{~mm}$ from the center of the interaural line in flat skull position; cannula length, $5 \mathrm{~mm}$ ] and connected by $3.5 \mathrm{~cm}$ vinyl tubing (size V/4, Bolab, Lake Havasu City, AZ) to an osmotic minipump (model 2002, Alza, Palo Alto, CA). Human recombinant EGF $(30 \mu \mathrm{g} / \mathrm{ml}$, Promega, Madison, WI) or FGF-2 (30 $\mu \mathrm{g} / \mathrm{ml}$, A. Baird, Prizm Pharmaceuticals, San Diego, CA) was dissolved in aCSF [(in mM): $148 \mathrm{NaCl}, 3$ $\mathrm{KCl}, 1.4 \mathrm{CaCl}_{2}, 0.8 \mathrm{MgCl}_{2}, 1.5 \mathrm{Na}_{2} \mathrm{HPO}_{4}$, and $0.2 \mathrm{NaH}_{2} \mathrm{PO}_{4}, \mathrm{pH}$ 7.4] containing $100 \mu \mathrm{g} / \mathrm{ml}$ rat serum albumin (Sigma, St. Louis, MO). An antibiotic (gentamycin, $50 \mu \mathrm{g} / \mathrm{ml}$, Sigma) was included in the infusate. The animals received EGF $(n=10)$, FGF-2 $(n=10)$, or aCSF $(n=10)$ at a flow rate of $0.50 \mu \mathrm{l} / \mathrm{hr}$, resulting in a delivery of $360 \mathrm{ng}$ of growth factor per day for $14 \mathrm{~d}$. During the last $12 \mathrm{~d}$ of the pump period animals received daily intraperitoneal injections of bromodeoxyuridine (BrdU, $50 \mathrm{mg} / \mathrm{kg}$, Sigma). At the end of the treatment one-half of the animals $(n=5$ per group) were anesthetized deeply and perfused intracardially with $4 \%$ paraformaldehyde in $100 \mathrm{~mm}$ phosphate buffer, $\mathrm{pH}$ 7.4. Brains were removed, post-fixed overnight in $4 \%$ paraformaldehyde, and transferred to $0.32 \mathrm{~m}$ sucrose. In the remaining one-half of the animals the pumps were removed under methoxyflurane anesthesia. The vinyl tubing was ligated with sterile nonabsorbable black monofilament nylon (3-0 Dermalon, American Cyanamid, Danbury, CT). These animals were perfused after an additional 4 week period without growth factor infusion.

\section{Histology}

The brains were cut in three parts, providing material for (1) coronal sections of the SVZ and hippocampus and sagittal sections of the (2) OB and (3) cerebellum. Sections $(40 \mu \mathrm{m})$ were cut with a sliding microtome and stored at $-20^{\circ} \mathrm{C}$ in a cryoprotectant solution (glycerol, ethylene glycol, and $0.1 \mathrm{M}$ phosphate buffer, $\mathrm{pH}$ 7.4, 3:3:4 by volume).

Antibodies and immunochemicals. The following antibodies and final dilutions were used: mouse (mo) $\alpha$-BrdU (1:400, Boehringer Mannheim, Indianapolis, IN), rat $\alpha$-BrdU (1:100, Accurate, Westbury, NY), mo $\alpha$-PSA-NCAM (1:2500, clone MenB kindly provided by Dr. G. Rougon, University of Marseille, Marseille, France), mo $\alpha$-NeuN (1:20, clone A60 kindly provided by Dr. R. Mullen, University of Utah, Salt Lake City, UT), rabbit $\alpha$-S100 $\beta$ (1:5000, Swant, Bellinzona, Switzerland), biotinylated horse $\alpha$-mouse IgG (1:160, Vector Laboratories, Burlingame, CA), avidin-biotin-peroxidase complex (1:100, Vectastain Elite, Vector Laboratories), and donkey $\alpha$-rat-FITC, $\alpha$-mouse-Texas Red, and $\alpha$-rabbitCY5 (all 1:300, Jackson ImmunoResearch, West Grove, PA).

Immunoperoxidase. Free-floating sections were treated with $0.6 \%$ $\mathrm{H}_{2} \mathrm{O}_{2}$ in TBS $(0.15 \mathrm{M} \mathrm{NaCl}$ and $0.1 \mathrm{M}$ Tris- $\mathrm{HCl}, \mathrm{pH} 7.5)$ for $30 \mathrm{~min}$ to block endogenous peroxidase. For DNA denaturation, sections were incubated for $2 \mathrm{hr}$ in $50 \%$ formamide $/ 2 \times \mathrm{SSC}(0.3 \mathrm{M} \mathrm{NaCl}$ and $0.03 \mathrm{M}$ sodium citrate) at $65^{\circ} \mathrm{C}$, rinsed for $5 \mathrm{~min}$ in $2 \times \mathrm{SSC}$, incubated for $30 \mathrm{~min}$ in $2 \mathrm{~N} \mathrm{HCl}$ at $37^{\circ} \mathrm{C}$, and rinsed for $10 \mathrm{~min}$ in $0.1 \mathrm{M}$ boric acid, $\mathrm{pH} 8.5$. Several rinses in TBS were followed by incubation in TBS/0.1\% Triton $\mathrm{X}-100 / 3 \%$ normal horse serum (TBS-Ths) for $30 \mathrm{~min}$ and incubation with mo $\alpha$-BrdU antibody in TBS-Ths overnight at $+4^{\circ} \mathrm{C}$. After being rinsed in TBS-Ths, sections were incubated for $1 \mathrm{hr}$ with biotinylated horse $\alpha$-mouse antibody. With intermittent rinses in TBS, avidin-biotinperoxidase complex was applied for $1 \mathrm{hr}$, followed by peroxidase detection for $5 \mathrm{~min}\left(0.25 \mathrm{mg} / \mathrm{ml} \mathrm{DAB}, 0.01 \% \mathrm{H}_{2} \mathrm{O}_{2}, 0.04 \% \mathrm{NiCl}\right)$.

Immunofluorescence. Sections were treated for DNA denaturation as described above, followed by several rinses in TBS and incubation in

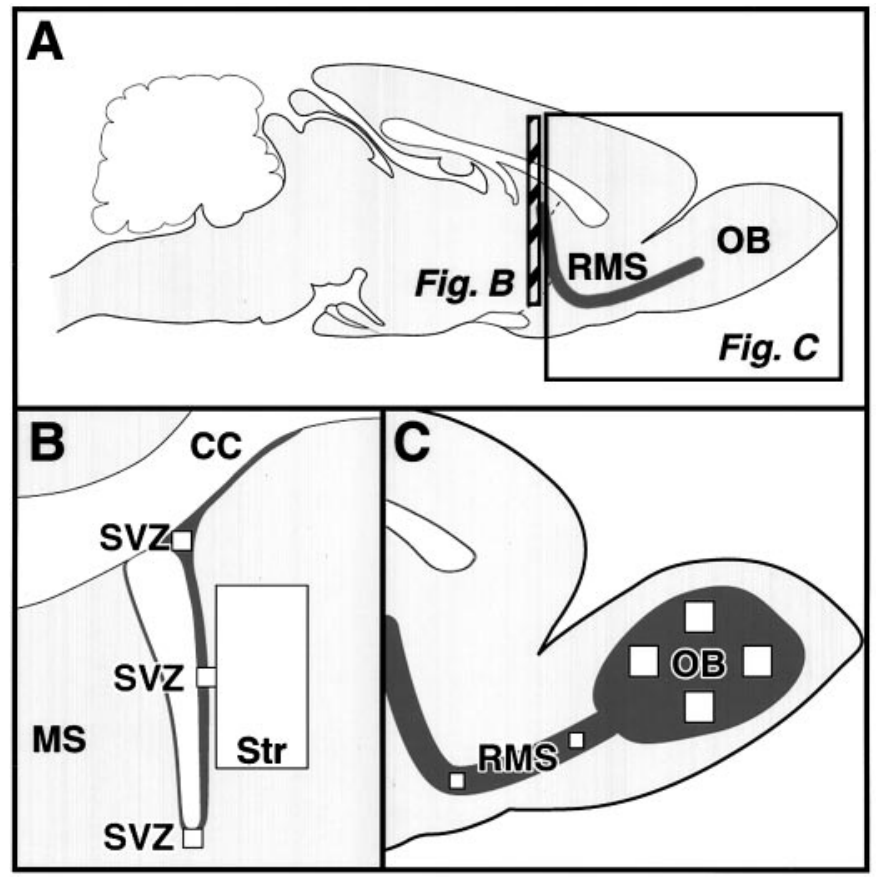

Figure 1. Analysis of the subventricular zone (SVZ) and olfactory bulb. $A$, Sagittal view of the rat brain illustrating the anatomical sites of progenitor proliferation in the $S V Z$, migration along the rostral migratory stream $(R M S)$, and differentiation in the olfactory bulb $(O B)$. Hatched bar indicates position of coronal view in $B$. $B$, Coronal plane of the lateral ventricle with the corpus callosum $(C C)$, medial septum $(M S)$, and striatum (Str). Three areas in the $S V Z$ (ventral, lateral, and dorsal squares, $50 \times 50 \mu \mathrm{m})$ and one area in the striatum (large rectangle, $300 \times 600 \mu \mathrm{m}$ ) were analyzed for BrdU-positive cells on each section. $C$, Parasagittal plane of frontal cortex and olfactory bulb. Two areas of the RMS (small squares, $50 \times 50 \mu \mathrm{m}$ ) and four areas of the $O B$ granule cell layer (large squares, $100 \times 100 \mu \mathrm{m})$ were analyzed for BrdU-positive cells and colabeling with NeuN or S100 $\beta$.

TBS/0.1\% Triton X-100/3\% normal donkey serum (TBS-Tds) for 30 min. Primary antibodies were applied in TBS-Tds for $48 \mathrm{hr}$ at $+4^{\circ} \mathrm{C}$, rinsed in TBS three times for $10 \mathrm{~min}$, and blocked in TBS-Tds for 10 min. Antibodies were detected with donkey $\alpha$-rat, mouse, or rabbit coupled to FITC, Texas Red, or CY5 for 2 hr. Fluorescent signals were detected and processed by a confocal scanning laser microscope (BioRad MRC1024, Hercules, CA) and Adobe Photoshop (Adobe Systems, Mountainview, CA).

\section{Quantification}

Quantification of BrdU-positive cells was accomplished with unbiased counting methods. The optical disector procedure (Sterio, 1984) was used to determine the three-dimensional numerical density of BrdUpositive cells, which is expressed as cells $/ \mathrm{mm}^{3}$. Structures were sampled either by selecting predetermined areas on each section (Fig. 1; SVZ, striatum, RMS, and OB) or by analyzing entire structures on each section (dentate gyrus and cerebellum). In the latter case we used a pointcounting grid for determination of the sampling volume via the Cavalieri method (Michel and Cruz-Orive, 1988).

Lateral ventricle and striatum. Every 12th section from a coronal series of the striatum was selected between AP $+10.6 \mathrm{~mm}$-genu corpus callosum - and AP $+8.74 \mathrm{~mm}$-anterior commissure crossing (Paxinos and Watson, 1986). As illustrated in Figure $1 B$, BrdU-positive cells were counted in three predetermined areas $(50 \times 50 \mu \mathrm{m})$ of the lateral ventricle wall on all selected sections. A rectangular area of the striatum $(300 \times 600 \mu \mathrm{m})$ was selected at a $50 \mu \mathrm{m}$ distance from the lateral ventricle wall and analyzed on each section. All BrdU-positive nuclei in these selected areas were counted and presented as the number of cells (in thousands) $/ \mathrm{mm}^{3}$ (Table 1).

$R M S$ and $O B$. Every sixth section $(40 \mu \mathrm{m})$ from sagittal series of the $\mathrm{OB} /$ frontal cortex was selected and stained for BrdU immunohistochem- 


\begin{tabular}{|c|c|c|c|c|}
\hline Area & $\mathrm{aCSF}$ & FGF-2 & EGF & \\
\hline \multicolumn{5}{|l|}{ Subventricular zone } \\
\hline \multicolumn{5}{|l|}{$1 \mathrm{~d}$ after infusion } \\
\hline Cannula side & $62.2 \pm 9.8$ & $208.5 \pm 62.2^{* *}$ & $595.5 \pm 133.1^{* *}$ & \\
\hline Contralateral side & $37.1 \pm 8.1$ & $32.6 \pm 4.4$ & $70.3 \pm 9.9^{* *}$ & \\
\hline \multicolumn{5}{|l|}{4 weeks after infusion } \\
\hline Cannula side & $30.6 \pm 10.7$ & $104.8 \pm 27.7^{* *}$ & $153.6 \pm 27.8^{* *}$ & \\
\hline Contralateral side & $13.3 \pm 3.9$ & $13.5 \pm 2.7$ & $88.0 \pm 11.8^{* *}$ & \\
\hline \multicolumn{5}{|l|}{ Rostral migratory str. } \\
\hline $1 \mathrm{~d}$ after infusion & $915.5 \pm 50.0$ & $714.4 \pm 38.0^{*}$ & $368.8 \pm 25.0^{* *}$ & \\
\hline \multicolumn{5}{|l|}{ Olfactory bulb } \\
\hline \multicolumn{5}{|l|}{4 weeks after infusion } \\
\hline Total & $40.9 \pm 2.0 \quad(100)$ & $46.9 \pm 1.2^{*} \quad(100)$ & $16.3 \pm 1.6^{* *}$ & $(100)$ \\
\hline Neurons & $39.3 \pm 1.6 \quad(96)$ & $45.2 \pm 0.9^{*}$ & $11.8 \pm 1.5^{* *}$ & $(72)$ \\
\hline Astrocytes & $0.16 \pm 0.11(<0.1)$ & $0.26 \pm 0.10 \quad(<0.1)$ & $2.26 \pm 0.54^{* *}$ & (14) \\
\hline \multicolumn{5}{|l|}{ Striatum } \\
\hline \multicolumn{5}{|l|}{4 weeks after infusion } \\
\hline Total & $2.8 \pm 0.4 \quad(100)$ & $6.1 \pm 0.8^{* *}(100)$ & $12.3 \pm 3.5^{* *}$ & $(100)$ \\
\hline Neurons & $0(0)$ & $0(0)$ & & $0(0)$ \\
\hline Astrocytes & $0.2 \pm 0.1$ & $1.4 \pm 0.4^{* *}(22)$ & $4.5 \pm 1.4^{* *}$ & (39) \\
\hline $\mathrm{BrdU}^{+} /$satellite cells & $1.1 \pm 0.1$ & $3.2 \pm 0.5^{*}$ & $5.2 \pm 1.1^{*}$ & (46) \\
\hline $\mathrm{BrdU}^{+} /$sat./astrocytes & $0.05 \pm 0.03(1.8)$ & $0.6 \pm 0.2^{*} \quad(10)$ & $1.7 \pm 0.7^{*}$ & (14) \\
\hline
\end{tabular}

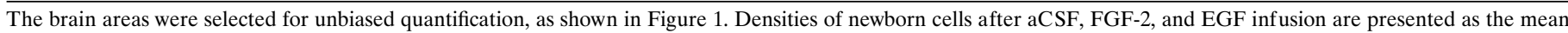

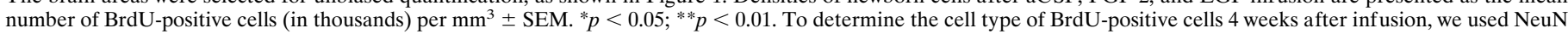
as a marker for neurons and $\mathrm{S} 100 \beta$ for astrocytes. Percentages of cell types (numbers in parentheses) are based on the total density of BrdU-positive cells.

istry. As depicted in Figure $1 C$, two predetermined areas $(50 \times 50 \mu \mathrm{m})$ in the RMS and four areas $(100 \times 100 \mu \mathrm{m})$ in the granule cell layer (GCL) of the OB were analyzed on each section. All BrdU-positive nuclei in these selected areas were counted and presented as the number of cells (in thousands) $/ \mathrm{mm}^{3}$ (Table 1).

Dentate gyrus. Every 12th section $(40 \mu \mathrm{m})$ from a coronal series was selected from each animal and processed for immunoperoxidase. Six sections from the dorsal hippocampus (AP +5.86 to $+2.96 \mathrm{~mm}$ ) were analyzed entirely for BrdU-positive cells in the molecular layer, the GCL, and the hilus. The subgranular zone, defined as a two-cell bodywide zone along the border of the GCL and the hilus, always was combined with the GCL for quantification. All BrdU-positive nuclei in these selected areas were counted and presented as cells (in thousands)/ $\mathrm{mm}^{3}$ (Table 2).

Cerebellum. On two sagittal sections of the cerebellum the fourth lobulus was analyzed entirely for the density of BrdU-positive cells in the molecular layer, GCL, and white matter. Cell numbers are expressed as BrdU-positive cells (in thousands) $/ \mathrm{mm}^{3}$ (Table 2).

Statistical analysis was performed with one-way ANOVA, followed by post hoc comparison with the Tukey post hoc test.

\section{RESULTS}

To study the effect of growth factors on the proliferation of adult neural progenitor cells in vivo, we chronically infused EGF, FGF-2, or aCSF for 2 weeks into the lateral ventricle of adult rats, using osmotic minipumps. BrdU was administered intraperitoneally during the period of growth factor infusion to label dividing cells. Animals either were killed on the last day of growth factor infusion to analyze the mitotic effect of the growth factors or were kept for an additional 4 weeks after terminating growth factor infusion to study the differentiation of the newborn cells. Both systems of adult neurogenesis, the SVZ/OB and dentate gyrus, were analyzed for BrdU-positive cells. The cerebellum served as a control area in the adult rat brain because it lacks detectable neurogenesis. To quantify the proliferation of neural progenitor cells and the survival of newborn cells after growth factor infusion, we determined the density of BrdU-positive cells by stereo- logical counting techniques. To characterize cell fate, we combined BrdU labeling with the astroglial marker S100 $\beta$, which labels astrocytic cell bodies (Boyes et al., 1986), and the neuronal marker NeuN, which recognizes neuronal cell bodies and nuclei (Mullen et al., 1992). The percentage of BrdU-positive cells colabeled either with $\mathrm{NeuN}$ or $\mathrm{S} 100 \beta$ was determined by triple immunofluorescence and confocal laser scanning microscopy and was multiplied by the overall density of BrdU-positive cells to determine the density of newborn neurons and astrocytes.

\section{EGF effects on proliferation and differentiation of neural progenitors}

Infusion of EGF induced a striking proliferation of the SVZ precursor population. Expansion of BrdU-positive cells was most pronounced in the lateral wall of the lateral ventricle (Fig. 2C). In addition, newborn cells were found in the medial and posterior circumference of the lateral ventricle, suggesting that progenitors also were recruited to divide in "quiescent" areas of the SVZ. Infusion of EGF resulted in "polyp-like" hyperplasias of the ventricle wall, which consisted of BrdU-positive cells that were immunonegative for either S100 $\beta$ or NeuN (Fig. 3). These EGFinduced hyperplasias had regressed completely after 4 weeks (Fig. 3C).

Quantification of the SVZ revealed a ninefold increase in the density of newborn cells over aCSF controls immediately after EGF infusion. The number of labeled cells present after 4 weeks remained increased relative to controls (Fig. 2, Table 1). There was also an increase in the number of labeled cells observed in adjacent areas, particularly in the striatum (Fig. $4 C$, Table 1), but also in cortex and septum (Fig. 4F,I), where the majority of newborn cortical cells was detected around the cannula tract (Fig. $4 F$ ). Interestingly, in the striatum triple labeling of BrdU-positive EGF-generated striatal cells with BrdU, NeuN, and S100 $\beta$ re- 


\begin{tabular}{|c|c|c|c|}
\hline Area & $\mathrm{aCSF}$ & FGF-2 & EGF \\
\hline \multicolumn{4}{|l|}{ Dentate gyrus } \\
\hline \multicolumn{4}{|l|}{$1 \mathrm{~d}$ after infusion } \\
\hline Granule cell layer & $5.60 \pm 0.49$ & $4.87 \pm 1.06$ & $7.77 \pm 1.10$ \\
\hline Hilus & $1.09 \pm 0.34$ & $1.14 \pm 0.22$ & $2.06 \pm 0.59$ \\
\hline Molecular layer & $0.66 \pm 0.11$ & $0.92 \pm 0.17$ & $3.69 \pm 0.32 * *$ \\
\hline \multicolumn{4}{|l|}{4 weeks after infusion } \\
\hline \multicolumn{4}{|l|}{ Granule cell layer } \\
\hline Total & $3.44 \pm 0.56(100)$ & $3.25 \pm 0.32(100)$ & $2.84 \pm 0.89$ \\
\hline Neurons & $3.19 \pm 0.52(93)$ & $2.91 \pm 0.27(90)$ & $1.50 \pm 0.52 * *(53)$ \\
\hline Astrocytes & $0.01 \pm 0.01(0.2)$ & $0.01 \pm 0.01(0.2)$ & $1.13 \pm 0.35 * *(40)$ \\
\hline Hilus & $0.57 \pm 0.17$ & $0.67 \pm 0.14$ & $1.02 \pm 0.22$ \\
\hline Molecular layer & $0.62 \pm 0.07$ & $0.70 \pm 0.10$ & $2.32 \pm 0.47^{* *}$ \\
\hline \multicolumn{4}{|l|}{ Cerebellum } \\
\hline \multicolumn{4}{|l|}{$1 \mathrm{~d}$ after infusion } \\
\hline Molecular layer & $0.081 \pm 0.019$ & $0.160 \pm 0.035$ & $0.133 \pm 0.027$ \\
\hline Granule cell layer & $0.065 \pm 0.027$ & $0.113 \pm 0.007$ & $0.065 \pm 0.025$ \\
\hline White matter & $0.084 \pm 0.041$ & $0.050 \pm 0.031$ & $0.082 \pm 0.018$ \\
\hline \multicolumn{4}{|l|}{4 weeks after infusion } \\
\hline Molecular layer & $0.069 \pm 0.008$ & $0.073 \pm 0.016$ & $0.094 \pm 0.009$ \\
\hline Granule cell layer & $0.079 \pm 0.007$ & $0.084 \pm 0.021$ & $0.123 \pm 0.017$ \\
\hline White matter & $0.079 \pm 0.012$ & $0.095 \pm 0.028$ & $0.152 \pm 0.027$ \\
\hline
\end{tabular}

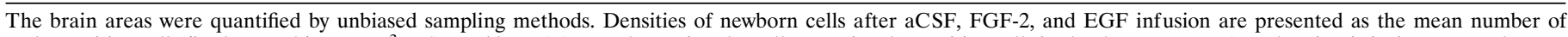

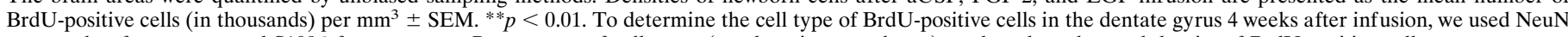
as a marker for neurons and $\mathrm{S} 100 \beta$ for astrocytes. Percentages of cell types (numbers in parentheses) are based on the total density of BrdU-positive cells.

vealed no BrdU-labeled neurons. Although a large number of BrdU-positive nuclei (45\%) were associated closely with neurons, three-dimensional confocal analysis revealed that the BrdUpositive nuclei belonged to a cell body located in a different focal plane (Fig. 5). These closely attached BrdU-positive cells frequently colabeled (up to $30 \%$ ) with $\mathrm{S} 100 \beta$, suggesting that these cells were satellite cells of glial origin. Because this finding stands in contrast to a previous report of EGF-induced neurogenesis in the adult mouse striatum (Craig et al., 1996), we reanalyzed the sections from the striatum and cerebral cortex of each EGFtreated animal (4 weeks after infusion) looking for cells that appeared to be double-labeled for BrdU and NeuN. Detailed confocal z-series analysis of 20 cells per animal revealed invariably that none of the BrdU-positive nuclei was contained within a NeuN-positive neuron. Thus, of a total of $>2800$ newborn cells scored, none were neurons.

Many of the cells born in the SVZ migrate along the RMS into the OB, where they differentiate into neurons (Corotto et al., 1993; Lois and Alvarez-Buylla, 1993). On their way to the OB the progenitor cells can undergo cell division as well as differentiation into neuroblasts that express early neuronal markers like TuJ1 (Bonfanti and Theodosis, 1994; Thomas et al., 1996). Four weeks after inf usion no residual BrdU-positive cells could be detected in the RMS (Fig. $6 F$ ). Although more cells are born in the SVZ in response to EGF treatment, significantly fewer BrdU-positive cells (40\% of aCSF control) are present in the RMS (Fig. $6 C$, Table 1). The number of newborn cells that reached the OB after 4 weeks of EGF infusion also was reduced significantly $(40 \%$ of the aCSF control, Table 1). PSA-NCAM, the polysialylated form of the neural cell adhesion molecule, appears to be required for migration of neuronal precursors within the RMS (Ono et al., 1994; Hu et al., 1996). Although PSA-NCAM expression was not quantified, it was detected by immunofluorescence labeling in all experimental groups (Fig. 6A-C). Therefore, EGF-induced reduction of newborn SVZ cells in the RMS was not attributable to the absence of PSA-NCAM after growth factor treatment. Triple immunofluorescence showed that the population of newborn cells that reached the GCL of the $\mathrm{OB}$ in control animals consisted of $\sim 96 \%$ neurons and $<0.1 \%$ astrocytes, whereas EGF not only reduced the number of cells reaching the bulb but also shifted the ratio toward a glial lineage ( $72 \%$ neurons/14\% astrocytes) (Fig. 7, Table 1). The absolute density of newborn glia increased from 160 cells $/ \mathrm{mm}^{3}$ in controls to 2260 cells $/ \mathrm{mm}^{3}$ (14-fold) after EGF treatment (Table 1). Therefore, the shift was not simply a relative increase in newborn glia because of a decrease in newborn neuronal cells but also indicated an increased de novo gliogenesis.

Within the hippocampus, cells born at the boundary between the hilus and GCL migrate into the GCL before differentiating into neurons. All three layers of the hippocampal dentate gyrus (molecular layer, GCL, and hilus) were analyzed for the density of newborn cells after EGF treatment. The molecular layer of EGF-treated animals demonstrated a significant increase in the number of BrdU-positive cells. The majority of these cells was found in the immediate vicinity of the wall of the third ventricle. In the hilus and GCL, where neurogenesis normally occurs, the number of newborn cells was not altered significantly at the end of EGF infusion or 4 weeks later (Table 2). In aCSF-treated animals $92 \%$ of the newborn cells differentiated into neurons and $<1 \%$ into astrocytes. In contrast, EGF changed this ratio to $52 \%$ neurons and 39\% astrocytes (Fig. 8, Table 2), inducing a shift toward the glial fate that was even more pronounced than in the OB. The absolute density of newborn glia increased from 10 cells $/ \mathrm{mm}^{3}$ in controls to 1130 cells $/ \mathrm{mm}^{3}$ (>100-fold) after EGF treatment (Table 1). Even more prominent than in the OB, the shift toward glial differentiation was attributable to an increased 
de novo gliogenesis and not merely a relative increase because of a decrease in newborn neuronal cells.

\section{FGF-2 effects on proliferation and differentiation of neural progenitors}

The density of newborn cells in the SVZ was increased by FGF-2, although to a lesser extent than by EGF, and the density of newborn cells into the adjacent striatal parenchyma was increased over aCSF controls (Figs. $2 B, 4 B$, Table 1). None of the BrdUpositive cells in the striatum of FGF-2-treated animals was double-labeled for NeuN, although some newborn cells in the striatum were juxtaposed closely to neuronal cell bodies, as seen in EGF animals. FGF-2 also decreased the number of BrdUpositive cells in the RMS at the end of infusion (Fig. 6B, Table 1). As with EGF infusion and in aCSF controls, no BrdU-positive cells were detectable in the RMS 4 weeks later (Fig. 6D-F). However, in contrast to the EGF animals, the number of BrdUpositive cells found in the GCL of the OB 4 weeks after FGF-2 infusion was increased significantly over controls (Table 1). This general increase in the density of newborn olfactory cells was accompanied by an increase of newborn neurons. The number of newborn glial cells was not altered significantly, although this was probably because of the infrequent detection of BrdU/S100 $\beta$ positive cells and a resulting high variance (Table 1).

In contrast to the SVZ/OB system, the generation of newborn cells in the hippocampal dentate gyrus was not affected by FGF-2 treatment. The ratio between newborn neurons and astrocytes also was not altered 4 weeks after FGF-2 treatment, indicating that both proliferation and differentiation of hippocampal progenitors were unaffected by the growth factor (Fig. 8, Table 2).

Analysis of newborn cells in the cerebellum revealed no significant changes at the end of growth factor treatment or 4 weeks after withdrawal of either growth factor (Table 2), indicating that this brain structure, which normally shows no adult neurogenesis, is unresponsive to these growth factors.

\section{DISCUSSION}

During development, growth factors provide important extracellular signals for regulating the proliferation and fate determination of stem and progenitor cells in the CNS (Calof, 1995). By infusing EGF and FGF-2 into the lateral ventricle of adult rats, we could show that the two populations of progenitors that continue to divide in the adult brain respond differently to these growth factors in vivo. Proliferation of hippocampal progenitors was unaffected by either EGF or FGF-2. In contrast, proliferation of subventricular progenitor cells increased after both FGF-2 and EGF administration, with EGF having a more dramatic effect. These findings are consistent with numerous in vitro studies that have shown that both factors can maintain responsive neural progenitors in cell cycle, thus expanding the progenitor population and delaying differentiation (Richards et al., 1992; Vescovi et al., 1993; Morshead et al., 1994; Sensenbrenner et al., 1994; Bouvier and Mytilineou, 1995; Gage et al., 1995a; Gritti et al., 1995, 1996; Palmer et al., 1995; Santa-Olalla and Covarrubias, 1995).

FGF-2 had a strong mitotic effect on the SVZ progenitors in vivo, but the migration of newborn cells in the RMS was diminished during the inf usion period. However, 4 weeks after FGF-2 inf usion, a larger number of newly generated cells were detected in the $\mathrm{OB}$, indicating an increased migration of SVZ progenitors after withdrawal of FGF-2. In vitro results suggest that FGF-2 has the potential to keep uncommitted progenitors in cell cycle and to delay differentiation (Vescovi et al., 1993; Bouvier and Mytilineou, 1995; Kilpatrick and Bartlett, 1995; Palmer et al., 1995; Gritti et al., 1996). The biphasic response of RMS cells to FGF-2 could be attributable to increased proliferation in the $\mathrm{SVZ}$, which reduces progenitor cell migration through the stream. After FGF-2 withdrawal a larger number of cells would be released into the RMS, generating more newborn cells in the OB 4 weeks later. Because $96 \%$ of the newborn olfactory cells differentiated into neurons, we conclude that FGF-2 had a stimulatory effect on the generation of OB neurons. However, because a very low number of newborn glial cells were detected here, conclusions about FGF-2induced changes of the glial cell population in the OB are not possible. EGF infusion also expanded the SVZ precursor population while decreasing the number of newborn cells in the RMS. However, in contrast to FGF-2, EGF withdrawal reduced neurogenesis in the OB, whereas the genesis of astrocytes was stimulated. Although olfactory neurogenesis involves separate areas for cell division (SVZ), migration (RMS), and differentiation (OB), recent studies have shown that cell division and neuronal commitment of progenitor cells can occur in the migratory stream (Bonfanti and Theodosis, 1994; Menezes et al., 1995; Lois et al., 1996; Thomas et al., 1996). Astrocytes in the RMS are typically neither proliferating nor participating in the migration (Lois and AlvarezBuylla, 1994; Lois et al., 1996). We assume that EGF acts on proliferation primarily in the SVZ and on differentiation primarily in the OB but also is influencing cells in the RMS.

Progenitor populations in SVZ and hippocampus were affected differently by EGF. EGF had no proliferative effect on hippocampal progenitors, whereas even progenitors in quiescent areas of the SVZ, such as the medial and posterior regions of the ventricular wall, were recruited by EGF to enter the cell cycle. Normally,

Figure 2. BrdU-positive cells in the SVZ at the end of and 4 weeks after intracerebroventricular inf usion of aCSF $(A, D)$, FGF-2 $(B, E)$, and EGF $(C$, $F)$. Note the large expansion of the SVZ and the density of newborn cells in the striatum after FGF-2 administration $(B)$, which are even more dramatic after EGF administration $(C)$. Proliferation was more pronounced on the side of the cannula, as compared with the contralateral side. Four weeks after growth factor withdrawal, a high density of BrdU-positive cells was still present in the SVZ of EGF-treated animals $(F)$. Scale bar in $A, 50 \mu \mathrm{m}$.

Figure 3. "Polyp-like" hyperplasia in the SVZ of EGF-treated animals at the end of treatment (2 weeks). $A$, High density of BrdU-positive cells at the convex pole of a hyperplasia, which protrudes into the CSF-filled ventricle. $B$, BrdU-positive cells are immunonegative for neuronal (NeuN, red) and astrocytic markers $(\mathrm{S} 100 \beta$, blue $)$. The ependymal layer $(\mathrm{S} 100 \beta$, blue $)$ is discontinuous (arrows) in areas of growth. $C$, Density of BrdU-labeled cells is still increased; however, the hyperplastic changes completely regress 4 weeks after EGF withdrawal. Scale bars in $A, C, 25 \mu \mathrm{m}$.

Figure 4. Increased number of BrdU-positive cells in the striatum $(A-C)$, cortex $(D-F)$, and medial septum $(G-I)$ of EGF- and FGF-2-treated animals at the end of infusion. $D-F$, Note the increase of BrdU-positive cells along the cannula tract in the cerebral cortex (on the left side of the images). Shown are confocal microscopic images with immunofluorescent triple labeling for BrdU (green), NeuN (red), and S100 $\beta$ (blue). Scale bar in $A$, $200 \mu \mathrm{m}$. 




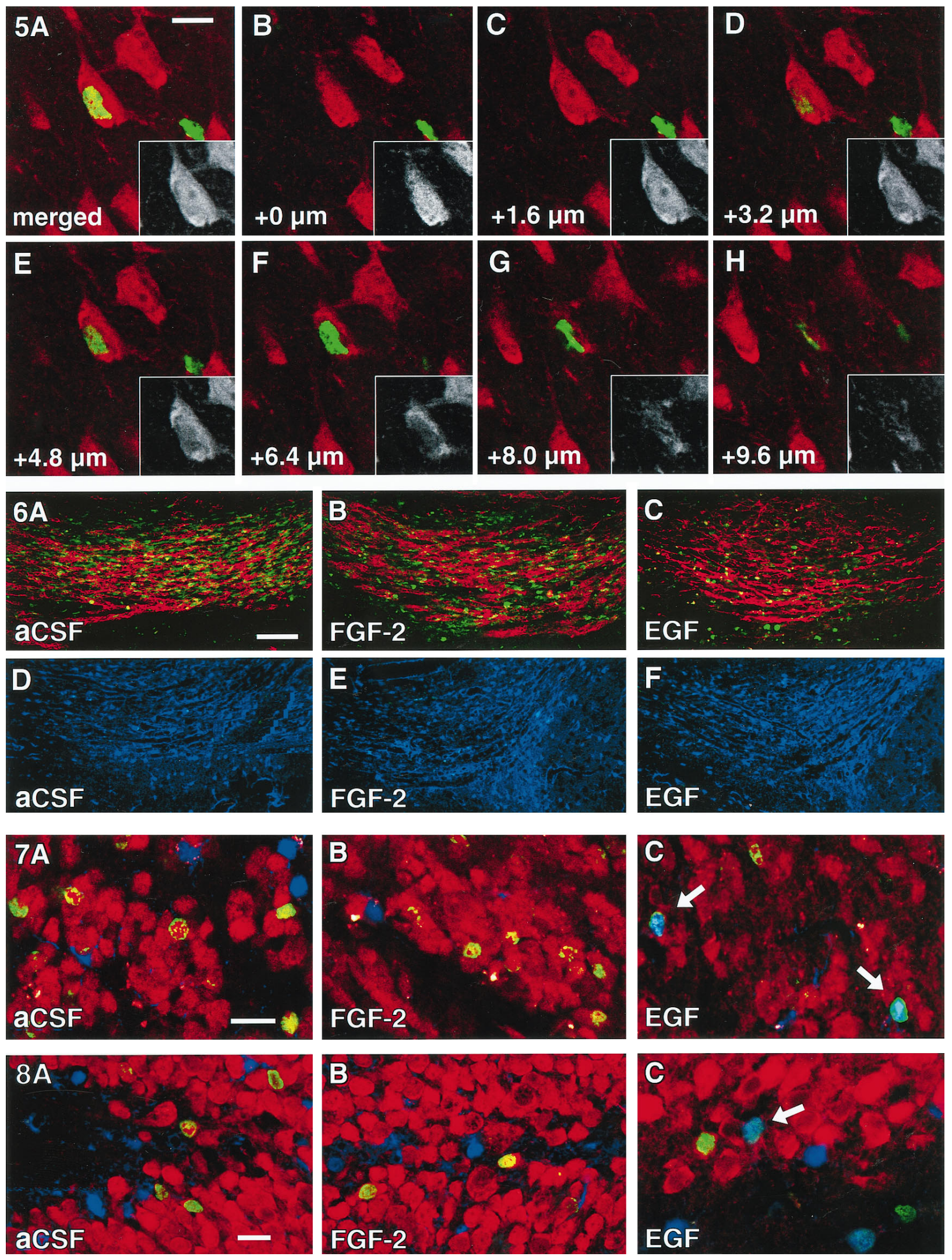


the majority of precursor cells from the SVZ and hippocampus differentiates into neurons in their appropriate target regions (Kaplan and Hinds, 1977; Bayer, 1983; Cameron et al., 1993). However, in animals treated with EGF, the ratio of newborn neurons to astrocytes was altered, favoring glial differentiation. Among others, three alternative underlying cellular mechanisms are possible. (1) EGF could have opposite effects on separate glial and neuronal precursor populations, thus inducing proliferation of glial and reducing proliferation of neuronal progenitors. (2) Another explanation involves the effect of cell death on changes in progenitor populations. Developmental studies have shown direct evidence (Gould et al., 1991; Naruse and Keino, 1995; Blaschke et al., 1996) and studies of adult neurogenesis have shown indirect evidence (Morshead and van der Kooy, 1992) that naturally occurring cell death might play an important role in controlling the number of neuronal progenitors from SVZ and hippocampus. Therefore, general stimulation of proliferation by EGF in combination with increased cell death of neuronal progenitors could produce an increase in newborn glial cells without having a specific stimulatory effect of glial progenitors. The data from SVZ/OB could be interpreted in this way, because the increase in SVZ proliferation is equivalent to the increase in newborn OB glia. However, in the hippocampus the $>100$-fold increase in gliogenesis is not matched by a significantly higher proliferation. (3) The recent finding that multipotent neural stem cells exist in the adult rodent brain (Kilpatrick and Bartlett, 1993; Lois and Alvarez-Buylla, 1993; Morshead et al., 1994; Gage et al., 1995b; Palmer et al., 1995; Gritti et al., 1996; Reynolds and Weiss, 1996; Svendsen et al., 1996) suggests that EGF infusion could stimulate proliferation of stem cells in the brain but also could influence the fate of these multipotent cells toward a glial lineage.

The limited effect of FGF-2 on hippocampal progenitors in vivo contrasts with previous reports of the ability of FGF to maintain proliferative hippocampal progenitors in vitro (Ray et al., 1993; Gage et al., 1995a). It may be possible that hippocampal progenitors in their natural environment are not responsive to exogenous FGF-2 in the dose provided in this study. Alternatively, low penetration efficiency might reduce the availability of FGF-2 in the brain parenchyma (Gonzalez et al., 1994). Improved penetration could be achieved by addition of soluble FGF-binding molecules, such as heparan sulfate proteoglycans, to the infusion solution to prevent rapid absorption of FGF-2 by extracellular matrix molecules during infusion (Rapraeger et al., 1994).

Our findings are in part consistent with and in part in contrast to a recent study in adult mice (Craig et al., 1996). As in our study, EGF induced an expansion of the SVZ and an increased density of newborn cells into the adjacent striatum, cortex, and septum (Fig. 4). Whether the newborn cells migrated into these areas or were stimulated locally cannot be decided from our data, because multiple BrdU injections prevent the exact determination of birth place and time for these cells. However, in contrast to our findings, immunofluorescent double labeling of striatal and cortical cells with NeuN and BrdU in the previous study in mice (Craig et al., 1996) had indicated that newborn cells showed a neuronal phenotype. In our study three-dimensional confocal analysis revealed that NeuN and BrdU invariably were detected in separate cells (Fig. 5). A portion of the BrdU-positive cells that were juxtaposed to the NeuN-immunoreactive neurons expressed S100 $\beta$, indicating that they were of astrocytic origin. Perineuronal satellite cells were described as early as 1913 by Ramón y Cajal as being positioned closely to neuronal perikarya and being of astrocytic and oligodendrocytic origin (Penfield, 1932; Ludwin, $1979,1984)$. However, not all of the closely juxtaposed cells were S100 $\beta$-positive, so we cannot exclude the possibility that some of the "unclassified" cells are uncommitted progenitor cells, which may differentiate into neurons at a later time point. In summary, although some experimental conditions, such as continuous EGF infusion, daily EGF doses, and immunohistochemical markers (BrdU, NeuN, and S100 $\beta$ ), were comparable between the two studies, species differences (rat vs mouse) and, in particular, different histological analyses may account for the discrepancies.

A surprising finding of chronic EGF stimulation was the induction of pronounced hyperplasias in the ventricular wall, which protruded into the CSF-filled space (Fig. 3). Although receptors for both EGF and FGF-2 are expressed by subependymal cells (Gonzalez et al., 1995; Weickert and Blum, 1995; Craig et al., 1996), only EGF induced this hyperplasia. Numerous studies have shown the involvement of the EGF receptor family in tumorogenesis of the CNS (for review, see Berger et al., 1992; Collins, 1995; von Deimling et al., 1995). Four weeks after treatment the EGFinduced hyperplasia regressed completely, indicating that the continuous presence of EGF was required for the abnormal growth.

\section{$\leftarrow$}

Figure 5. Close association of neurons with newborn cells (satellite cells). A, A NeuN-positive neuron (red and black/white inset) appeared to be colabeled with BrdU in a merged image resembling a regular fluorescent microscope image. $B-H$, Z-series analysis revealed that the NeuN-positive neuronal cell body is situated in a different focal plane from the BrdU-positive nucleus. Note that the NeuN-positive nucleus with nucleolus is visible in $C$ and the BrdU-positive nucleus in $E$ and $F$. Scale bar in $A, 10 \mu \mathrm{m}$.

Figure 6. Reduced rostral migration of BrdU-positive cells at the end of EGF and FGF-2 infusions. Compared with aCSF controls $(A)$, the number of BrdU-positive cells ( green) in the RMS is decreased in FGF-2 $(B)$ and decreased further in EGF-treated animals $(C)$. However, PSA-NCAM (red), which is required for migration of progenitors within the RMS, is present in all groups. No BrdU-positive cells can be found at 4 weeks after infusion $(D-F)$. Images $D-F$ are immunofluorescent double labelings for $\mathrm{BrdU}$ (green) and $\mathrm{S} 100 \beta$ (blue). Note that scanning parameters for the confocal microscope are identical for $A-F$. Scale bar in $A, 50 \mu \mathrm{m}$.

Figure 7. Cellular phenotype of newborn cells in the olfactory bulb. Cells in the olfactory granule cell layer were characterized at 4 weeks after inf usion of aCSF $(A)$, FGF-2 $(B)$, or EGF $(C)$ for BrdU ( green), NeuN (red), and S100 $\beta($ blue). After aCSF or FGF- 2 treatment the vast majority of newborn cells double labels for NeuN ( green/red). Note the reduced number of BrdU-positive cells that reach the olfactory bulb in EGF-treated animals $(C$; see also Table 1). The differentiation of EGF-induced progenitors was shifted toward a glial lineage. Arrows indicate newborn astrocytes ( green/blue). Scale bar in $A, 20 \mu \mathrm{m}$.

Figure 8. Cellular phenotype of newborn cells in the dentate gyrus. Cells in the hippocampal granule cell layer were characterized at 4 weeks after infusion of aCSF $(A)$, FGF-2 $(B)$, or EGF $(C)$ for BrdU ( green), NeuN (red), and S100 $\beta($ blue). After aCSF or FGF-2 treatment the vast majority of newborn cells double labels for NeuN ( green/red). The differentiation of EGF-induced progenitors has shifted toward a glial lineage $(C)$. Arrow indicates a newborn astrocyte (green/blue). Scale bar in $A, 20 \mu \mathrm{m}$. 
In vitro models have been excellent tools for analyzing signals that influence the proliferation and fate of neural progenitor cells, but it has been difficult to determine how well these in vitro observations relate to signaling in vivo. By testing mitogens known to be effective in vitro, we have been able to show that progenitor populations in the adult rodent brain respond, in part, differently from in vitro. The site-specific responsiveness of progenitors to exogenous factors indicates that local cues play an important role in regulating neurogenesis in vivo. In the absence of in vivo signals, progenitors cultured in the presence of EGF proliferate and differentiate into neurons and glia, yet, in vivo, EGF has a stimulatory influence on proliferation and the genesis of glia but an unexpected limiting effect on the generation of neurons. This dichotomy emphasizes the importance of obtaining in vivo and in vitro results to identify more completely the factors that direct site-specific neuronal differentiation.

\section{REFERENCES}

Altman J, Das GD (1965) Autoradiographic and histological evidence of postnatal hippocampal neurogenesis in rats. J Comp Neurol 124:319-335.

Bayer SA (1983) ${ }^{3} \mathrm{H}$-thymidine-radiographic studies of neurogenesis in the rat olfactory bulb. Exp Brain Res 50:329-340.

Berger F, Laine M, Hoffmann D, Verna JM, Charffanet M, Chauvin C, Rost N, Nissou MF, Benabid AL (1992) The EGF receptor pathway in human cerebral tumors. Neurochirurgie 38:257-266.

Blaschke AJ, Staley K, Chun J (1996) Widespread programmed cell death in proliferative and postmitotic regions of the fetal cerebral cortex. Development 122:1165-1174.

Bonfanti L, Theodosis DT (1994) Expression of polysialylated neural cell adhesion molecule by proliferating cells in the subependymal layer of the adult rat, in its rostral extension, and in the olfactory bulb. Neuroscience 62:291-305.

Bouvier MM, Mytilineou C (1995) Basic fibroblast growth factor increases division and delays differentiation of dopamine precursors in vitro. J Neurosci 15:7141-7149.

Boyes BE, Kim SU, Lee V, Sung SC (1986) Immunohistochemical colocalization of S-100b and the glial fibrillary acidic protein in rat brain. Neuroscience 17:857-865.

Calof AL (1995) Intrinsic and extrinsic factors regulating vertebrate neurogenesis. Curr Opin Neurobiol 5:19-27.

Cameron HA, Woolley CS, McEwen BS, Gould E (1993) Differentiation of newly born neurons and glia in the dentate gyrus of the adult rat. Neuroscience 56:337-344.

Cattaneo E, McKay R (1991) Identifying and manipulating neuronal stem cells. Trends Neurosci 14:338-340.

Collins VP (1995) Gene amplification in human gliomas. Glia 15:289-296.

Corotto FS, Henegar JA, Maruniak JA (1993) Neurogenesis persists in the subependymal layer of the adult mouse brain. Neurosci Lett 149:111-114.

Craig CG, Tropepe V, Morshead CM, Reynolds BA, Weiss S, van der Kooy D (1996) In vivo growth factor expansion of endogenous subependymal neural precursor cell populations in the adult mouse brain. J Neurosci 16:2649-2658.

Gage FH (1994) Neuronal stem cells: their characterization and utilization. Neurobiol Aging 15(Suppl 2):S191.

Gage FH, Coates PW, Palmer TD, Kuhn HG, Fisher LJ, Suhonen JO, Peterson DA, Suhr ST, Ray J (1995a) Survival and differentiation of adult neuronal progenitor cells transplanted to the adult brain. Proc Natl Acad Sci USA 92:11879-11883.

Gage FH, Ray J, Fisher LJ (1995b) Isolation, characterization, and use of stem cells from the CNS. Annu Rev Neurosci 18:159-192.

Goldman JE (1995) Lineage, migration, and fate determination of postnatal subventricular zone cells in the mammalian CNS. J Neurooncol 24:61-64.

Gonzalez AM, Carman LS, Ong M, Ray J, Gage FH, Shults CW, Baird A (1994) Storage, metabolism, and processing of ${ }^{125}$ I-fibroblast growth factor-2 after intracerebral injection. Brain Res 665:285-292.

Gonzalez AM, Berry M, Maher PA, Logan A, Baird A (1995) A comprehensive analysis of the distribution of FGF-2 and FGFR1 in the rat brain. Brain Res 701:201-226.
Gould E, Woolley CS, McEwen BS (1991) Naturally occurring cell death in the developing dentate gyrus of the rat. J Comp Neurol 304:408-418.

Gritti A, Cova L, Parati EA, Galli R, Vescovi AL (1995) Basic fibroblast growth factor supports the proliferation of epidermal growth factorgenerated neuronal precursor cells of the adult mouse CNS. Neurosci Lett 185:151-154.

Gritti A, Parati EA, Cova L, Frolichsthal P, Galli R, Wanke E, Faravelli L, Morassutti DJ, Roisen F, Nickel DD, Vescovi AL (1996) Multipotential stem cells from the adult mouse brain proliferate and self-renew in response to basic fibroblast growth factor. J Neurosci 16:1091-1100.

Hauke C, Ackermann I, Korr H (1995) Cell proliferation in the subependymal layer of the adult mouse in vivo and in vitro. Cell Prolif 28:595-607.

Hu H, Tomasiewicz H, Magnuson T, Rutishauser U (1996) The role of polysialic acid in migration of olfactory bulb interneuron precursors in the subventricular zone. Neuron 16:735-743.

Kaplan MS, Bell DH (1983) Neuronal proliferation in the 9-month-old rodent-radioautographic study of granule cells in the hippocampus. Exp Brain Res 52:1-5.

Kaplan MS, Hinds JW (1977) Neurogenesis in the adult rat: electron microscopic analysis of light radioautographs. Science 197:1092-1094.

Kilpatrick TJ, Bartlett PF (1993) Cloning and growth of multipotential neural precursors: requirements for proliferation and differentiation. Neuron 10:255-265.

Kilpatrick TJ, Bartlett PF (1995) Cloned multipotential precursors from the mouse cerebrum require FGF-2, whereas glial restricted precursors are stimulated with either FGF-2 or EGF. J Neurosci 15:3653-3661.

Kuhn HG, Dickinson-Anson H, Gage FH (1996) Neurogenesis in the dentate gyrus of the adult rat: age-related decrease of neuronal progenitor proliferation. J Neurosci 16:2027-2033.

Levison SW, Goldman JE (1993) Both oligodendrocytes and astrocytes develop from progenitors in the subventricular zone of postnatal rat forebrain. Neuron 10:201-212.

Levison SW, Chuang C, Abramson BJ, Goldman JE (1993) The migrational patterns and developmental fates of glial precursors in the rat subventricular zone are temporally regulated. Development 119:611-622.

Lewis PD (1968) A quantitative study of cell proliferation in the subependymal layer of the adult rat brain. Exp Neurol 20:203-207.

Lois C, Alvarez-Buylla A (1993) Proliferating subventricular zone cells in the adult mammalian forebrain can differentiate into neurons and glia. Proc Natl Acad Sci USA 90:2074-2077.

Lois C, Alvarez-Buylla A (1994) Long-distance neuronal migration in the adult mammalian brain. Science 264:1145-1148.

Lois C, Garcia-Verdugo JM, Alvarez-Buylla A (1996) Chain migration of neuronal precursors. Science 271:978-981.

Ludwin SK (1979) The perineuronal satellite oligodendrocyte. A role in remyelination. Acta Neuropathol (Berl) 47:49-53.

Ludwin SK (1984) The function of perineuronal satellite oligodendrocytes: an immunohistochemical study. Neuropathol Appl Neurobiol 10:143-149.

Luskin MB (1993) Restricted proliferation and migration of postnatally generated neurons derived from the forebrain subventricular zone. Neuron 11:173-189.

Luskin MB, McDermott K (1994) Divergent lineages for oligodendrocytes and astrocytes originating in the neonatal forebrain subventricular zone. Glia 11:211-226.

Menezes JRL, Smith CM, Nelson KC, Luskin MB (1995) The division of neuronal progenitor cells during migration in the neonatal mammalian forebrain. Mol Cell Neurosci 6:496-508.

Michel RP, Cruz-Orive LM (1988) Application of the Cavalieri principle and vertical sections method to lung: estimation of volume and pleural surface area. J Microsc 150:117-136.

Morshead CM, van der Kooy D (1992) Postmitotic death is the fate of constitutively proliferating cells in the subependymal layer of the adult mouse brain. J Neurosci 12:249-256.

Morshead CM, Reynolds BA, Craig CG, McBurney MW, Staines WA, Morassutti D, Weiss S, van der Kooy D (1994) Neural stem cells in the adult mammalian forebrain: a relatively quiescent subpopulation of subependymal cells. Neuron 13:1071-1082.

Mullen RJ, Buck CR, Smith AM (1992) NeuN, a neuronal specific nuclear protein in vertebrates. Development 116:201-211.

Naruse I, Keino H (1995) Apoptosis in the developing CNS. Prog Neurobiol 47:135-155. 
Ono K, Tomasiewicz H, Magnuson T, Rutishauser U (1994) N-CAM mutation inhibits tangential neuronal migration and is phenocopied by enzymatic removal of polysialic acid. Neuron 13:595-609.

Palmer TD, Ray J, Gage FH (1995) FGF-2-responsive neuronal progenitors reside in proliferative and quiescent regions of the adult rodent brain. Mol Cell Neurosci 6:474-486.

Paxinos G, Watson C (1986) The rat brain in stereotaxic coordinates. San Diego: Academic.

Penfield W (1932) Neuroglia and microglia, the interstitial tissue of the central nervous system. In: Special cytology (Cowdry EV, ed), pp 1147-1182. New York: Hoeber.

Privat A, Leblond CP (1972) The subependymal layer and neighboring region in the brain of the young rat. J Comp Neurol 146:277-302.

Rapraeger AC, Guimond S, Krufka A, Olwin BB (1994) Regulation by heparan sulfate in fibroblast growth factor signaling. Methods Enzymol 245:219-240.

Ray J, Peterson DA, Schinstine M, Gage FH (1993) Proliferation, differentiation, and long-term culture of primary hippocampal neurons. Proc Natl Acad Sci USA 90:3602-3606.

Reynolds BA, Weiss S (1992) Generation of neurons and astrocytes from isolated cells of the adult mammalian central nervous system. Science 255:1707-1710.

Reynolds BA, Weiss S (1996) Clonal and population analyses demonstrate that an EGF-responsive mammalian embryonic CNS precursor is a stem cell. Dev Biol 175:1-13.

Richards LJ, Kilpatrick TJ, Bartlett PF (1992) De novo generation of neuronal cells from the adult mouse brain. Proc Natl Acad Sci USA 89:8591-8595.
Santa-Olalla J, Covarrubias L (1995) Epidermal growth factor (EGF), transforming growth factor-alpha (TGF-alpha), and basic fibroblast growth factor (bFGF) differentially influence neural precursor cells of mouse embryonic mesencephalon. J Neurosci Res 42:172-183.

Sensenbrenner M, Deloulme JC, Gensburger C (1994) Proliferation of neuronal precursor cells from the central nervous system in culture. Rev Neurosci 5:43-53.

Sterio DC (1984) The unbiased estimation of number and sizes of arbitrary particles using the disector. J Microsc 134:127-136.

Suhonen JO, Peterson DA, Ray J, Gage FH (1996) Differentiation of adult hippocampus-derived progenitors into olfactory neurons in vivo. Nature 383:624-627.

Svendsen CN, Clarke DJ, Rosser AE, Dunnett SB (1996) Survival and differentiation of rat and human epidermal growth factor-responsive precursor cells following grafting into the lesioned adult nervous system. Exp Neurol 137:376-388.

Thomas LB, Gates MA, Steindler DA (1996) Young neurons from the adult subependymal zone proliferate and migrate along an astrocyte, extracellular matrix-rich pathway. Glia 17:1-14.

Vescovi AL, Reynolds BA, Fraser DD, Weiss S (1993) bFGF regulates the proliferative fate of unipotent (neuronal) and bipotent (neuronal/ astroglial) EGF-generated CNS progenitor cells. Neuron 11:951-966.

von Deimling A, Louis DN, Wiestler OD (1995) Molecular pathways in the formation of gliomas. Glia 15:328-338.

Weickert CS, Blum M (1995) Striatal TGF-alpha: postnatal developmental expression and evidence for a role in the proliferation of subependymal cells. Brain Res Dev Brain Res 86:203-216. 